\title{
Problems and Countermeasures in the Development of Characteristic Towns in Sichuan Based on the Survey of Longtai Town
}

\author{
Yapping Jiang ${ }^{1, *}$ Binyu $\mathrm{Hu}^{1}$ \\ ${ }^{1}$ College of Commerce, Chengdu University, Chengdu, Sichuan 610000, China \\ *Corresponding author. Email:15828430146@163.com
}

\begin{abstract}
With the implementation of the rural revitalization strategy, creating a number of distinctive small towns with complete industries and long-term development has become the focus of a new round of high-level urbanization. This article analyzes the characteristics of characteristic towns, summarizes the experience and problems in the construction of characteristic towns in Longtai Town, Sichuan Province, and provides "Longtai Experience" for Sichuan characteristic towns.
\end{abstract}

Keywords: characteristic town, experience, problems, Sichuan

\section{INTRODUCTION}

The 13th Five-Year Plan proposes that in order to realize China's rural development, a number of characteristic small towns and small towns with distinctive industrial characteristics, prominent cultural characteristics and beautiful and livable environments will be constructed. Longtai Town, as the first batch of characteristic towns in Sichuan Province and the second batch of the top 100 pilot towns in the country, demonstrates its experience in industrial development and competition. For other towns in Sichuan, relying on their own industrial, geographical, and cultural advantages, they can create distinctive brands It has a strong reference significance.

\section{RESEARCH METHODS}

This study uses the discussion method and the field survey method to analyze the construction experience of the characteristic towns of Longtai Town and restrict the development bottlenecks.

\section{CONCEPT AND CHARACTERISTICS OF CHARACTERISTIC TOWNS}

\section{A. The concept of characteristic towns}

The new urbanization evolution of characteristic towns is an inevitable result. The formation of a characteristic town is a systematic evolution, which depends on the long-term local cultural accumulation and material characteristics. The essence of a characteristic town as a development platform that is independent of the city and different from the government industrial park, has a clear industrial positioning, distinctive cultural connotation characteristics, and integrates tourism, cultural innovation, and community functions. The construction theories of foreign characteristic towns are rural city theory, satellite city theory, grey area theory, new town movement theory, self-centered development theory, and sharing space theory. The construction of characteristic towns in China can be divided into three modes: the "Southern Jiangsu Model", relying on the geographical advantage of close to large urban agglomerations to establish large-scale township collective enterprises to support urban development; "Wenzhou Model", completing capital accumulation through private companies represented by families and then develop characteristic towns; "Pearl River Delta Model", developing outward-oriented economy through characteristic towns.

\section{B. Characteristics of characteristic towns}

According to the notification requirements of the Ministry of Housing and Urban-Rural Development, the National Development and Reform Commission, and the Ministry of Finance to cultivate characteristic towns, characteristic towns should have distinctive features, industrial development, green ecology, and beautiful and livable characteristics.

\section{THE CURRENT EXPERIENCE AND PROBLEMS OF SPECIAL TOWN CONSTRUCTION IN LONGTAI TOWN}

\section{A. Longtai construction experience}

1) Full support of policies: In exploring the development of the Longtai lemon industry, through 
interviews, our development government played a decisive role in the development of its industry. In the 1970 s, it was discovered that the economic value of lemons was the government's overall plan for the establishment of the Lemon Industry Bureau to guide farmers to expand the planting area. When it comes to the tree banner and pointing direction. Today, Anyue County has set up a special government research center to help the lemon industry. It has built a pillar industry from the entire process of breeding, seedlings, pest control, quarantine, and sales, forming a "governmentled, owner-driven, big-household guidance, and mass participation" Industrial pattern.

2) Lemon brand advantage: As the birthplace of Chinese lemons, Anyue Lemons have the brand advantage of "Chinese Lemons In Anyue, Anyue Lemons In Longtai", and are national geographical indication products. It won a gold medal on Thailand International Fruit Fair. Nearly $80 \%$ lemons are roughly machined and directed sold in Longtai. At the same time, as the only lemon distribution center in the country, nearly $90 \%$ of the nation's lemon sales channels are in the hands of Longtai people. Based on such innate advantages, Anyue has completed the stable production in production place, channel control, and sales. At the same time, the investigation found that the current domestic lemon sales channels were developed by the first batch of Longtai people who went out to market, they also made a contribution to opening up a stable market for Longtai Lemon and establishment of the Lemon brand.

3) Diversified supply and marketing paths: The survey found that there are 15 professional lemon marketing companies in Longtai Town (including external companies, local cooperatives, and local companies), more than 300 large marketing households, 5 e-commerce platforms, more than 500 e-commerce households, and 2 logistics companies and more than 200 frozen warehouses, integrated production, and sales, online and offline integration, multi-channel marketing for individuals, cooperatives, and companies. Diversified sales paths have solved the problem of slow sales of Longtai Lemon. The existence of large households has increased the premium capacity of the Longtai lemon market; the new rural planting model created by the cooperatives has brought new ways for local farmers to increase production and income. Market sales can not only solve the sales problems that farmers are most worried about, but also ensure market stability.

4) Brands promote cultural development: To achieve industrial upgrading, Longtai relies on ecological resources and historical heritage to develop the Tertiary Industry and accelerate the economic pattern of giving priority to planting and focusing on multiple industries. Longtai focuses on the lemon industry, grasping the "China Lemon Capital" business card, and continuing tapping lemon culture, deepening the cultural brand, singing the lemon economic theme, establishing the lemon spirit, and showing the local culture of Longtai, based on the brand of the cradle of Chinese lemons, that is, to visit the lemon garden-enjoy the lemon blossoms-eat a lemon feast-enjoy a lemon tea-drink lemon wine-sing a lemon song-dance a lemon dance-shoot a lemon movie, and then to take the Lemon Carnival as a carrier, and take advantage of Chengdu's K818 / K817 trips to and from Beijing's west. The "Lemon Capital of China" promoted lemon culture, allowing Longtai Lemon to travel across China's land with the pace of trains.

\section{B. Longtai construction issues}

1) Urban development planning is not scientific enough: The lemon industry in Longtai Town started early. The Lemon Industry Planning Bureau was established in the 1980s, but there are still big problems in land use planning, industrial layout, and market construction. There is not enough land for storage. The lemon warehouse that has been built now can not accommodate the storage of the low-price months. The level of deep processing of lemons is low. Currently, the lemons in Longtai are mainly rough processing, mainly for picking, removing bags, selecting, and packing. There are still relatively very a few companies in the industries of grinding lemon oil, making lemon masks, and preserved fruit. The government has not done enough in corporate planning and industrial upgrading, and the effect is not obvious.

2) Public infrastructure is incomplete: The chaotic streets, incomplete infrastructure, lack of garbage disposal, and poor river environment are urgent problems in the process of constructing high-level characteristic towns in Longtai. The level of pavement on Longtai's street is not high, there is no uniform standard for the stalls in front of the shop floor, and the silt accumulated along the Longtai River. The construction of beautiful towns is still a big problem for Longtai at present.

3) The population is aging seriously and the industry cannot retain labor: A major problem facing rural areas is how to control the outflow of the population. Longtai also has the phenomenon of a large number of young labor outflows under the background of population aging. The survey shows that more than $80 \%$ of workers in Longtai are old and less than $20 \%$ are young. People walking on Longtai are mostly old 
people and children. On the one hand, it shows that the problem of aging caused by the large number of young people going out in rural areas is really serious; on the other hand, it shows that the Longtai government has not done enough in local employment. Interviews found that companies are now unable to attract young people to work for long periods. This phenomenon is mainly due to the lack of attractiveness in rural areas subject to infrastructure. It is difficult for young people to endure boring life in rural areas and still, numbers of the young prefer working in cities with low wages.

\section{THE COUNTERMEASURES TO THE PROBLEMS IN THE CONSTRUCTION OF CHARACTERISTIC TOWNS IN LONGTAI TOWN}

\section{A. Improving industry guidance and standardizing management}

To go further on the road of characteristic towns, Longtai must perfect its industrial planning and vigorously develop the Secondary Industry and Tertiary Industry. The foundation of the Primary Industry has been solid. In the process of industrial transformation and upgrading, the government should give roles to the pioneering spirit of the 1970s, do a good job of government planning, seize the market, guide the development of the industry, strengthen management, and provide the upgrading of Anyue lemon industry. Greater support should be provided to ensure that Anyue Lemon goes global.

\section{B. Improving public facilities and creating conditions for tourism in the lemon industry}

The construction of public facilities in Longtai should attain goals: the streets are clean and tidy, the market is regulated and orderly, and the transportation is convenient and fast. In this way, social harmony and happiness can be achieved. Perfect public facilities are the foundation of the foundation. To deepen the lemon brand, refine the lemon culture, and develop lemon tourism, a complete infrastructure, reasonable travel route planning for attractions, and distinctive lemon tourist areas are needed. Only when the government takes a multi-pronged approach to strengthen infrastructure construction, dig deeper into the lemon element, and create a distinctive tourist town, can we open up a new situation.

\section{Strengthening the implementation of policies and retaining the population}

The local economy needs to stay alive then there should be enough the population. Longtai should strengthen investment in infrastructure construction, basic education, medical care, culture, and other aspects to ensure that more locals are willing to stay in the countryside for employment and attract foreign populations to stay and develop. From the Longtai Development Planning Division, it is understood that Longtai is currently preparing to build another primary school, a high school, and a hospital. At the same time of drainage, it can settle the staff of Longtai and add strength to the construction of Longtai's characteristic towns.

\section{Protecting the ecological environment and achieving sustainable development}

Blue sky, white clouds, green mountains, and green water are the most important issues for tourists. A good ecological environment is the basis of rural tourism. The relationship between resource development and utilization and ecological environmental protection must be properly handled. "Concepts like good environment can bring people wealth should be strengthened. Longtai itself is an agricultural town, and green is the nature of small-town construction. Longtai must adopt a scientific attitude and method to develop and utilize tourism resources in an orderly manner, to truly realize the win-win situation of tourism economic development and ecological environment improvement.

\section{CONCLUSION}

Characteristic small towns have developed rapidly in China's urbanization due to they are small and sophisticated towns, complete industrial characteristics, and strong cultural and tourist attractions. Sichuan is rich in products, has unique geographical advantages, and is blessed with blue sky and white clouds. Each town is born with the foundation for developing characteristic towns. Southwest and northwestern Sichuan are rich in farming characteristics and ethnic regional characteristics. Localities need to dig deep into local advantages to build regional brands, build cultural and creative industries with a unique value, and develop the local economy.

\section{References}

[1] Self-organized governance and planning response of characteristic towns - from the perspective of villagers' marginalization [A]. Liang Xiaoxiao. Sharing and Quality Proceedings of the 2018 China Urban Planning Annual Meeting (19 Small Town Planning) [C]. (in Chinese)

[2] Research on the Evolution of Characteristic Towns from the Perspective of Innovation Ecosystem [D]. Zhang Min. Suzhou University 2018 (in Chinese)

[3] Promoting the Construction of Characteristic Towns in Sichuan Province with High Quality [J]. Zhou Jie. Economic Research Guide. 2019 (23) (in Chinese)

[4] Developing Characteristic Industries and Realizing New-type Urbanization - Theoretical Mechanism and Economic Effect of "Characteristic Town" Model [J]. Tang Gang. Business Research. 2019 (06) (in Chinese) 
[5] On the Theoretical and Practical Innovations in the Construction of Characteristic Towns [J]. Zhang Hongyan. Famous Chinese Cities. 2017 (01) (in Chinese)

[6] "Integrated Governance": A Theoretical Explanation of Local Government Operational Behaviors [J]. Zhou Luyao. Journal of Zhejiang University (Humanities and Social Sciences). 2015 (06) (in Chinese)

[7] Review of Foreign Rural Space Reconstruction Studies [J]. Chen Xiaohua, Cao Mengying. Journal of Anhui Agricultural University. 2019 (02) (in Chinese)

[8] Cultural Brand Construction of Characteristic Towns from the Perspective of Brand Gene Theory: An Investigation Focused on Wuzhen [J]. Jiang Ling. Journal of Guizhou University (Social Science Edition). 2019 (05) (in Chinese) 